\title{
RESTABILIZATION OF THE POSTCRITICAL EQUILIBRIUM OF ELASTIC SYSTEMS
}

\author{
Gaik A. Manuylov, Sergey B. Kosytsyn, Maxim M. Begichev \\ Russian University of Transport (MIIT), Moscow, RUSSIA
}

\begin{abstract}
The application of the Appel-Vozlinsky theorem on the stability or instability conditions for bifurcation points of conservative elastic systems with a symmetric bifurcation diagram to evaluate restabilization possibility of structures under loads substantially larger than the first critical force. It is shown that restabilization is possible if the first eigenvalue of the Hesse matrix is a continuous alternating function of the load parameter, and the remaining eigenvalues are sign-definite quantities. The examples of the systems with restabilization are given: a high Mises girder and an elastic system composed of compressible rods.
\end{abstract}

Keywords: equilibrium, restabilization, bifurcation point, stability

\section{О ВОЗМОЖНОСТИ РЕСТАБИЛИЗАЦИИ ЗАКРИТИЧЕСКОГО РАВНОВЕСИЯ НЕКОТОРЫХ УПРУГИХ СИСТЕМ}

\author{
Г.А. Мануйлов, С.Б. Косицын, М.М. Бегичев
}

Российский университет транспорта (МИИТ), г. Москва, РОССИЯ

\begin{abstract}
Аннотация: Рассматриваются особенности применения теоремы Аппеля-Возлинского об условиях устойчивости или неустойчивости точек бифуркации консервативных упругих систем с симметричной бифуркационной диаграммой, к вопросам возможной рестабилизации при нагрузках, существенно больших первой критической. Показано, что рестабилизация возможна, если первое собственное значение матрицы Гессе есть непрерывная знакопеременная функция от параметра нагрузки, а остальные собственные значения - знакопостоянные величины. Приведены примеры систем с рестабилизацией: высокая ферма Мизеса и упруго сочлененная система, составленная из сжимаемых стержней.
\end{abstract}

Ключевые слова: равновесие, рестабилизация, точка бифуркации, устойчивость

\section{SYMMETRIC SYSTEMS, SYMMETRIC DIAGRAMS OF BIFURCATION AND APPEL - VOZLINSKY THEOREM}

Appel-Vozlinsky theorem formulates stability (or instability) conditions of bifurcation points for so-called "entirely symmetric systems". Such systems include all elastic systems with symmetric bifurcation diagram as it is shown in Figure 1. Usually, these systems have two plane (two directions) of symmetry (rods, plates, flat and spatial frames or trusses, symmetric arches, some symmetric shells and another structures). Let us note two important moments:
1) Changing of the stability character of the basic equilibrium always is caused by reaching of the first bifurcation point (at $\mathrm{P}_{\mathrm{kp} \mathrm{min}}=\mathrm{P}_{\text {bifl }}$ ), and it not always occurs at reaching of high bifurcation points.

2) Stability character of "new" equilibrium forms, branching out from the basic equilibrium in the bifurcation point, is determined by stability or instability of this bifurcation point in accordance with V.T. Stability character of "new" equilibriums branching out from the basic one in the bifurcation point is determined by stability or instability of this bifurcation point (W. T. Koiter [1]). 

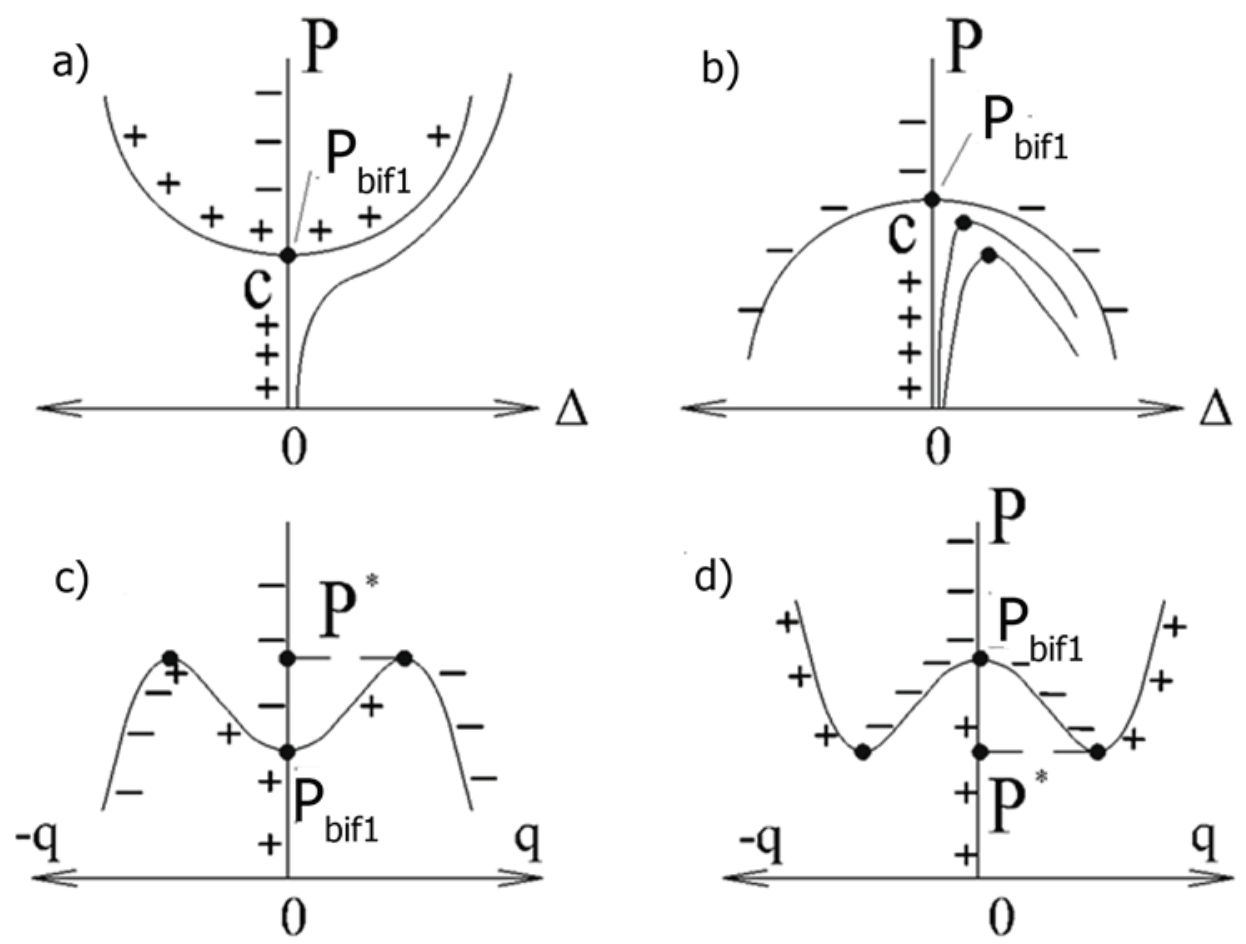

Figure 1. Bifurcation diagrams for scenarios "fold" and "butterfly": a, c) standard "butterfly" and "fold"; $b, d$ ) dual "butterfly" and "fold"; $P^{*}$ is critical load in the ultimate point.

Further, let us note that symmetric bifurcation point appears if decomposition of full potential energy to power series by bifurcation coordinate corresponds to features of the failure type "fold":

$$
V \approx q^{4}+\varepsilon_{2} q^{2}+\varepsilon_{1} q
$$

or standard "butterfly" type [2]:

$$
V \approx q^{6}+\varepsilon_{4} q^{4}+\varepsilon_{3} q^{3}+\varepsilon_{2} q^{2}+\varepsilon_{1} q
$$

The stability of the "first" bifurcation points at

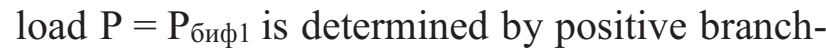
es of these features $\left(+q^{4}\right.$ and $\left.+q^{6}\right)$. Negative signs of branches $\left(-q^{4}\right.$ and $\left.-q^{6}\right)$ give instability symmetric diagrams. Types of symmetric diagrams which presented in figures 1 (a) and 1(b) corresponds to features of "fold" as well as feature of "butterfly" at some combination of managing parameters $\left(\varepsilon_{1}-\varepsilon_{4}\right)$. Here the distinctive feature is existing of only two "new" postbifurcation half-branches of equilibrium states. However, in the case of "butterfly" feature it is possible such combination of parameters, when near bifurcation point an elastic system have not two, but four "new" equilibrium states at some range of load $\mathrm{P}$ values as it is shown in figures 1 (c) and 1 (d). In accordance with diagrams in figure 1 the system has 4 "new" states of postcritical equilibrium at the range of loads $\mathrm{P}_{\text {bif }}$ $\mathrm{P}^{*}$ (that is until ultimate points will be reached). There are only two $\left(\mathrm{P}<\mathrm{P}_{\text {bifl }}\right.$, figure $1 \mathrm{c}$, and $\mathrm{P}>\mathrm{P}_{\text {bifl }}$, figure $1 \mathrm{~d}$ ) or none post critical equilibriums (figure $1 \mathrm{c}$ at $\mathrm{P}>\mathrm{P}^{*}$, and figure $1 \mathrm{~d}$ at $\mathrm{P}<\mathrm{P}^{*}$ ) beyond the boundary of these "new" postcritical equilibriums' ranges.

Appel-Vozlinsky theorem [3-5] allows us to predict a character of the closest bifurcation point: stability of symmetric bifurcation point is determined by stability single equilibrium halfbranch closing to it (from the side of load values, that smaller $\left(P<P_{b i f}\right)$ or larger $\left(\mathrm{P}>\mathrm{P}_{\mathrm{bif}}\right)$ than bifurcation load.

Presented in figures 1 (a) and 1 (c) single halfbranch, closing to bifurcation point, is sustainable branch of OC. Hence, the first bifurcation point at load $\mathrm{P}_{\mathrm{bif1}}$ is sustainable. Also growing 
"new" branches of postbifurcation equilibriums are sustainable.

On the contrary, single half-branches of systems with bifurcation diagrams by types presented in figures $1 \mathrm{~b}$ and $1 \mathrm{~d}$ are unsustainable the basic postbifurcation equilibriums (at $\mathrm{P}>\mathrm{P}_{\text {bifl }}$ ). Consequently, bifurcation point is unsustainable as well as new branching out equilibriums "falling" by load. Unsustainable equilibrium branches are signed as "“-“.

Let us note, that bifurcation diagrams $P=P(q)$ are intersection line for surfaces of equilibriums near bifurcation curvature $(d V / d q=0)$ and plane POq (at null value of initial imperfection parameter $\left.\xi_{1}\left(\xi_{1}=0\right)\right)$. Possible variants of symmetric sustainable diagrams, that have simple bifurcation points for systems with codimension less or equal 4 (number of managing parameters), are bounded by diagrams as it is shown in figures 1 (a) - 1 (d). However, AppelVozlinsky theorem also is acceptable to symmetric system with large (even) number of managing parameters.

Let us note for system with two or in some cases 4 managing parameters, that sufficient condition of simple symmetric bifurcation point stability (figures $1 \mathrm{a}, 1 \mathrm{c}$ ) is singularity and stability of under critical equilibrium.

Necessary stability condition is geometric symmetry of system and symmetry of acting loads. However, this condition is not sufficient.

The sufficient instability condition for simple symmetric bifurcation point is singularity and instability of initial (basic) postbifurcation equilibriums' half-branch (figure1 b).

It should be noted, that V.I. Vozlinsky formulated and proved theorem of stability (instability) of symmetric bifurcation point in 1967 [3]. However, formulation of the same theorem can be found in the paper of P. Appel [5], the original of which appeared in 1932. There it was written "... Stability character in the curvature with vertical tangential is the same if it would be in half-branch of "intersecting" curvature that is not bounded by branches of the first ones (that is singular).

\section{ENERGY MEANING OF BIFURCATION POINTS AND CHANGING STABILITY CHARACTER OF THE BASIC EQUILIBRIUM STATE}

In accordance with energy position the bifurcation point of the basic equilibrium appears then and only then, when there is orthogonal in energy aspect non-null addition component D. Reaching of bifurcation point by load (or kinematic compression) proves that basic subcritical stress-strain state exhausts possibilities to accumulate growing energy of an elastic deformation, caused by load rising, in the form, specified by initial (sub bifurcation) stress-strain state.

System self-organizes to have possibility to continue loading. It switches on additional accumulators to absorb new portions of potential energy of elastic deformation. Such additional forms are "new" equilibrium forms, that do not exist at subcritical equilibrium but exist in non-null addition $\mathrm{D}$, that have spoken before. If such addition is null $(\mathrm{D}=0)$, then bifurcation loss of stability becomes impossible. This aspect is determined by form of the first null Eigen vector $W_{1}^{0}$, calculated for subcritical equilibrium $\left(\mathrm{P}=\mathrm{P}_{\mathrm{cr}}-\right.$ $0)$. If this vector is orthogonal to external load vector [5]

$$
\vec{W}_{1}^{0} \perp \vec{P} \Rightarrow\left(\vec{P} \cdot \vec{W}_{1}^{0}\right)=0,
$$

then critical point is bifurcation point, the initial stress-strain state of which is filled by new components [6]. It principally allows to continue loading of the system.

If reduced scalar product is not equal to zero, then loss of stability occurs at ultimate point. For this point, the "null" eigen vector $\left(\vec{W}_{1}^{0}\right)$ of subcritical equilibrium usually is similar to form of such equilibrium [7]. Therefore, there is not any postcritical addition of subcritical equilibrium at reaching ultimate point. Critical equilibrium is unsustainable and system searching for a new sustainable equilibrium transforms to dynamic splash state. 
However, at bifurcation case or reaching of ultimate point a "new" initial postcritical equilibrium $\mathrm{W}_{\mathrm{i} / \text { postcr }}$ is a sum of subcritical equilibrium $\mathrm{W}_{\text {subcr }}$ and "null" eigen vector, taken with scale factor $\xi$ :

$$
W_{\text {н/пкр }}=W_{\text {предкр }}+\xi W_{1}^{0}
$$

\section{CHANGING OF STABILITY FORM AT BIFURCATION POINT AND RESTABILIZATION OF THE BASIC EQUILIBRIUM}

It is believed that at the reaching of the bifurcation point there is always a change in the quality of the equilibrium: the sustainable equilibrium existing before bifurcation point reached becomes unsustainable after the bifurcation point exceeds this value (at load $\mathrm{P}=\mathrm{P}_{\text {bif }}+\xi$ ). In general, this is always true only for the first bifurcation point (or for the first point on the "new" postcritical equilibrium branch of the secondary bifurcation). There are many systems for which, when passing by the basic equilibrium of the second, third, ..., $\mathrm{m}$-th bifurcation point $(\mathrm{m}=2,3$, ... $\mathrm{m}, \ldots)$, the instability property acquired by this equilibrium as a result of the first bifurcation point does not change after passing the higher bifurcation points. In other words, the stability of the basic equilibrium under load above the first bifurcation is not restored. An example of a such situation is an ordinary Eulerian rod (Figure 2), for which the "new" compressed-curved forms of equilibrium branching out in the second, third and subsequent points of bifurcation-increasing by load and unsustainable equilibrium. After loss of stability at passing of the first bifurcation point, further the basic linear equilibrium remains unsustainable (Fig. 2) at all load values, exceeding the first critical one $\left(\mathrm{P}>\mathrm{P}_{\mathrm{bifl}}\right)$. In the figure 2, unsustainable branches of postcritical equilibrium are marked with crosses; sustainable forms are shown by solid lines.

Sustainable postbifurcation equilibrium is compressed-curved equilibrium (at P $>$ Pcr1) branching out at the first point of bifurcation. At "high- er" "curved" forms of "new" equilibriums that branch out from the main linear equilibrium at

$$
\begin{gathered}
P_{\kappa p 2}=2 \pi^{2} E I / l^{2}, \\
P_{\kappa p 3}=3 \pi^{2} E I / l^{2}, \ldots \\
P_{\kappa p m}=m \pi^{2} E I / l^{2},
\end{gathered}
$$

all of these equilibriums may really exist and can be observed, if we input additional cross hinge supports at nodes (or equivalent points of bend). Then the higher critical load $\mathrm{P}_{\text {кр } 2,} \mathrm{P}_{\text {кр} 3}, \ldots$, $\mathrm{P}_{\mathrm{crm}}$, acquire a certain "optimization" meaning. For example, the second critical load of $\mathrm{P}_{\mathrm{cr} 2}$ is the highest critical load for a double-hinged rod with one intermediate support.

If this support is placed in the middle point of the rod, it divides rod into two identical and equal-sustainable parts, each of which does not affect the stability margin of the neighbor one. Equal-stability property gives

$$
\max P_{\kappa p}=4 \pi^{2} E I / l^{2} .
$$

Strict energy proof of the instability of all "higher" buckling forms of the compressed $\mathrm{Eu}-$ lerian rod was given by E. Reyes [6]. He showed that at the same norms (the same values for all forms of the sinusoid amplitudes) the values of the full potential energy for the first form $\mathrm{V}_{1}$ and the higher forms of buckling $\mathrm{V}_{2}, \ldots$, $\mathrm{V}_{\mathrm{n}}$ form a steadily increasing sequence.

$$
V_{1}<V_{2}<V_{3}<\ldots<V_{m}<\ldots
$$

All members of this sequence are greater than the value of the first member $V_{1}$ corresponding to the potential energy of the stable first form of the post-bifurcation equilibrium. Therefore, if you compress the Euler rod by load, exceeding the third critical load (for system with additional hinge supports), and further remove the supports, the compressed-curved s-form will instantly become unsustainable and "switch" on the first sustainable post-critical form of Euler elastics, corresponding to value of acting load. 


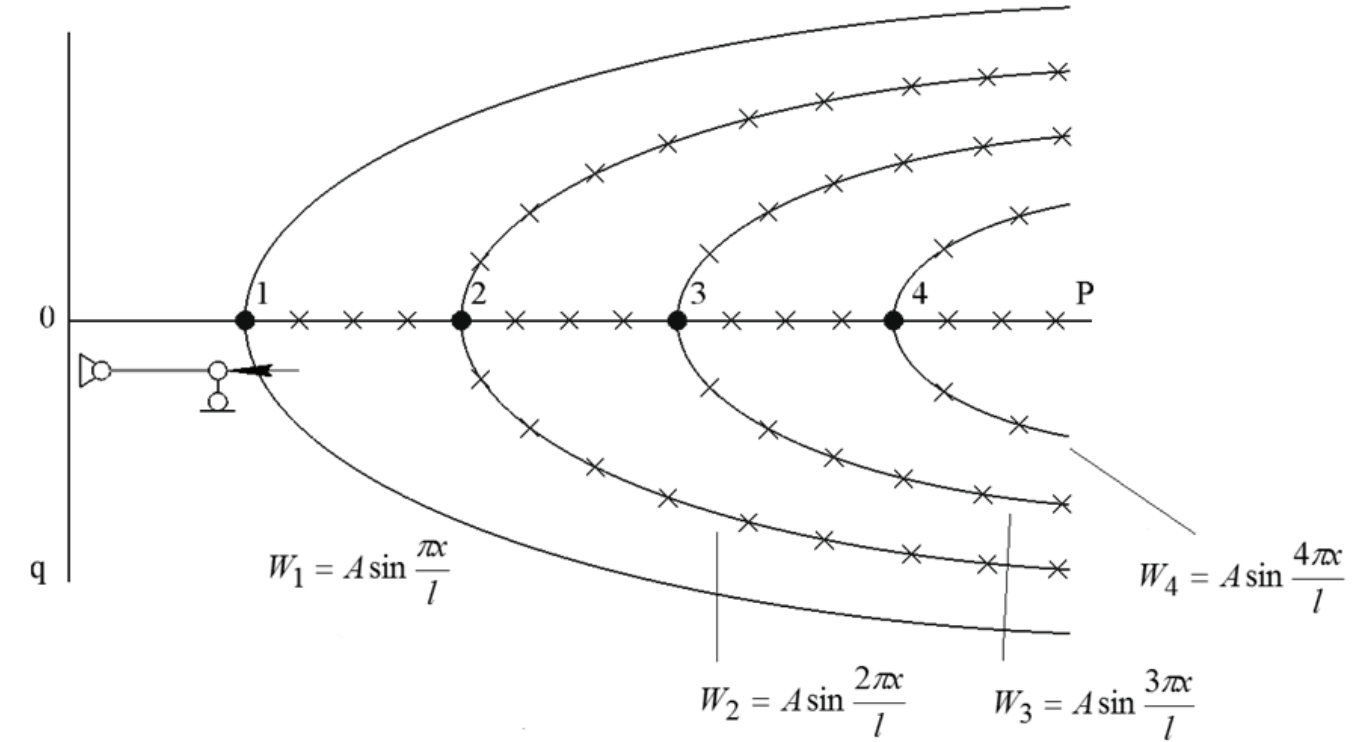

Figure 2. Sustainable (first) and unsustainable (all following) branches of the "new" compressed-curved equilibriums that bifurcate from the basic linear equilibrium of a Eulerian rod in the first and higher bifurcation points.

In accordance with the above, it should be note that the "new" higher forms of post-bifurcation equilibrium growing by load are not always forms of sustainable equilibrium. The equilibrium curve should grow by load to achieve condition when it consists of points corresponding to sustainable equilibrium. But this requirement is only a necessary but not sufficient sign of the stability of the mentioned above equilibriums. An additional requirement is that the loadincreasing equilibriums have a minimum potential energy. Just considered the highest forms of post-critical equilibrium of Euler rod are a good "reverse" illustrations to this provisions. At the same time, the "falling " (descending) branches of equilibrium are always unsustainable.

Theorem 1. For systems with a symmetric bifurcation diagram, it is possible to restabilize the basic equilibrium after passing an even number of the bifurcation point (2nd, 4th, etc.) if:

a) at each point of bifurcation the basic equilibrium changes the nature of stability;

b) "new" equilibriums branching out from this point of bifurcation $(\mathrm{m}=2,3,4 \ldots)$ are rising and unsustainable (Fig. 3).

Without reducing the generality of reasoning, let us consider a symmetric system with two degrees of freedom, which has a bifurcation diagram, as it is shown in Figure 3, and the basic equilibrium loses its stability when $\mathrm{P}>$ Рбиф1 and it becomes unsustainable in the interval of loads $\mathrm{P}_{\mathrm{bif}}$ $<\mathrm{P} \leq \mathrm{P}_{\text {bif2. }}$. These equilibriums under loads $\mathrm{P}<$ $\mathrm{P}_{\mathrm{bif} 2}$ form a single half-branch suitable to the second bifurcation point from the left. Therefore, according to theorem Appel-Vozlisky, the second bifurcation point "is not sustainable"; the branching out at this point the "new" equilibriums, increasing by the load, also are unsustainable. According to the condition, the change in the nature of the stability of the basic equilibrium after passing the second bifurcation point, this equilibrium should become sustainable at $\mathrm{P}>$ $\mathrm{P}_{\text {bif2. }}$. This theorem has been proved.

Note that the nature of stability of "new" equilibriums branching out at the first bifurcation point (at $\mathrm{P}=\mathrm{P}_{\mathrm{bifl}}$ ) does not affect the conditions of this theorem. But if we assume that the "new" equilibriums branching out at the second bifurcation point (at $\mathrm{P}=\mathrm{P}_{\text {bif }}$ ) form unsustainable "falling" branches (Fig. 3), then the basic equilibrium under load $\mathrm{P}>\mathrm{P}_{\text {bif2 }}$ should also be unsustainable. But this provision contradicts the condition of changing the nature of the stability of the basic equilibrium in the bifurcation points. Therefore, there is not restabilization in this case. 
For conservative systems, the possibility of restabilization of the basic equilibrium is determined by the behavior of the eigenvalues $\mu 1(\mathrm{P})$, $\mu 2(\mathrm{P}), \ldots, \mu \mathrm{n}(\mathrm{P})$ of the Hesse matrix of the total potential energy as a function of the parameter $P$. If the numbers are monotonically decreasing functions of $\mathrm{P}$

$$
\left(\frac{d \mu_{1}}{d p}<0, \frac{d \mu_{2}}{d p}<0, \ldots, \frac{d \mu_{n}}{d p}<0\right)
$$

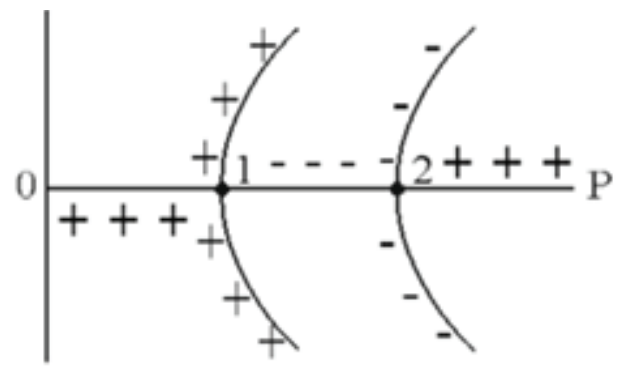

q

a)

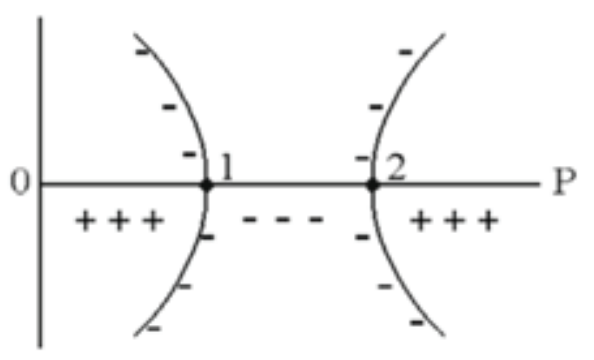

q

c) and each function passes through zero (from positive values to negative) to its point of bifurcation, then restabilization of the basic (initial) equilibrium at loads greater than the first critical $\left(\mathrm{P}>\mathrm{P}_{\mathrm{crl}}=\mathrm{P}_{\text {bifl }}\right)$ is impossible (example - elastic frame system).

If the degeneration of the Hessian matrix at the bifurcation points is associated with zero padding only one function $\mu 1(\mathrm{P})$ (in this case it must be alternating), and all other numbers are positive functions (Fig. 4), then the basic equilibrium can be restabilized in the intervals loads of $\mathrm{P}_{\text {bif } 2} \leq \mathrm{P} \leq \mathrm{P}_{\text {bif3 }}, \mathrm{P}_{\text {bif } 4}<\mathrm{P}<\mathrm{P}_{\text {bif5 }}$ and so on.

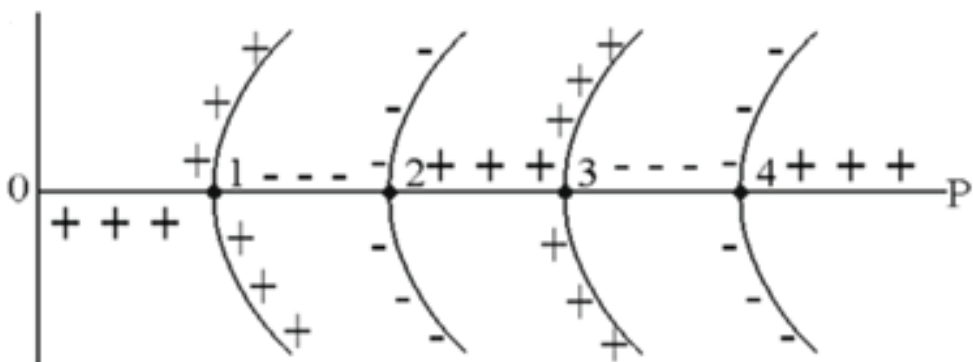

q

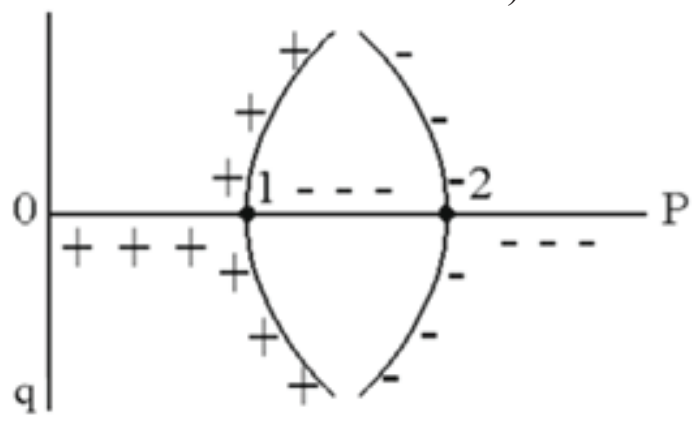

d)

Figure 3. An illustration of Theorem 1 on the conditions for re-stabilization.

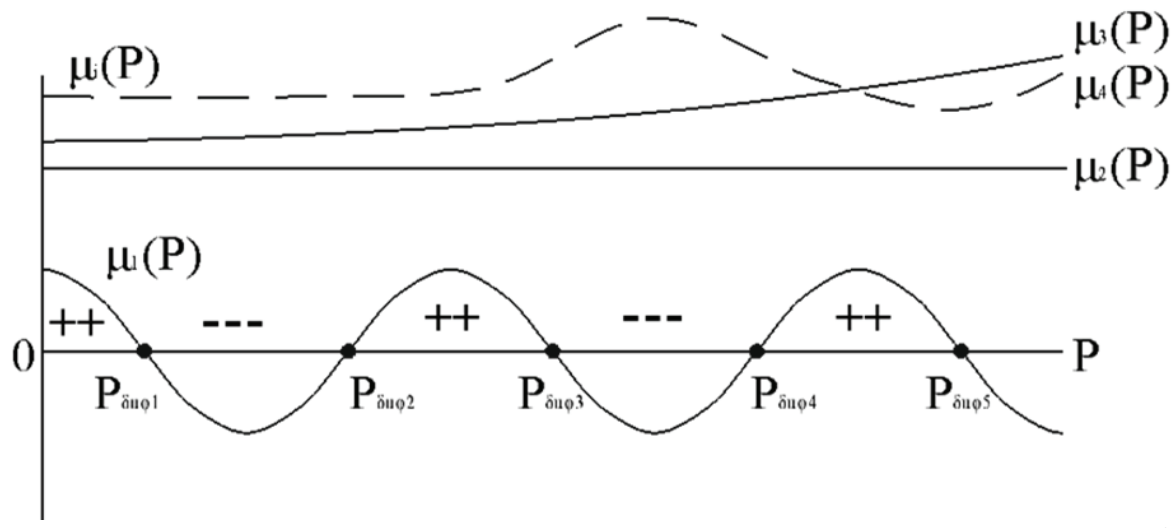

Figure 4. The graph of changes in the eigenvalues of the matrix NE: - $\mu 1(P)$ periodic function. 


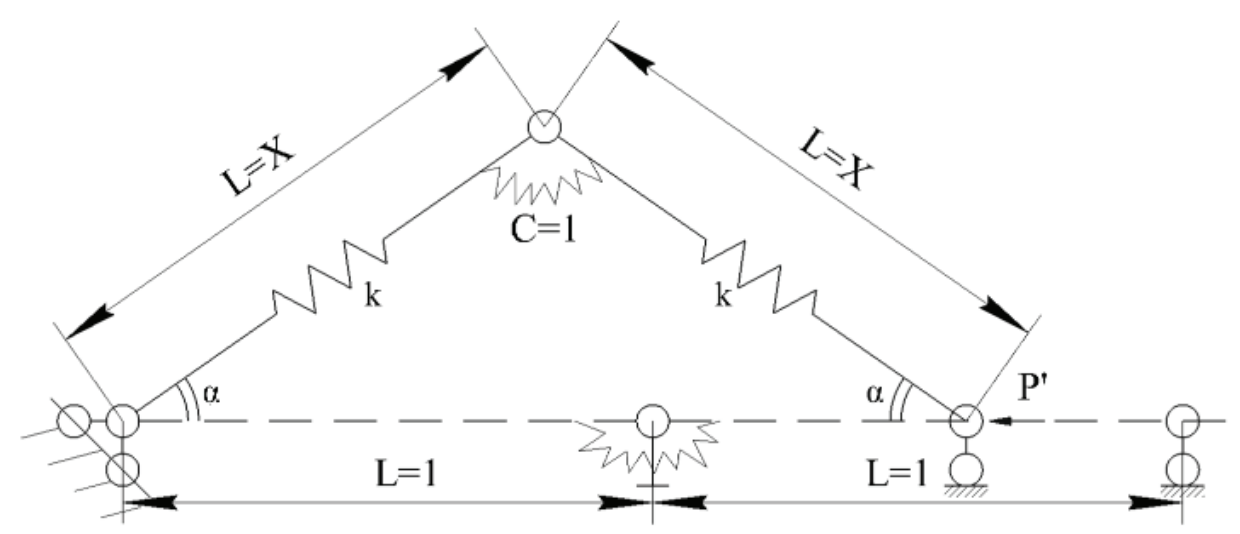

Figure 5. To the problem of the stability of straight-linear equilibrium of a system of 2 compressible rods connected by an elastically-flexible hinge.

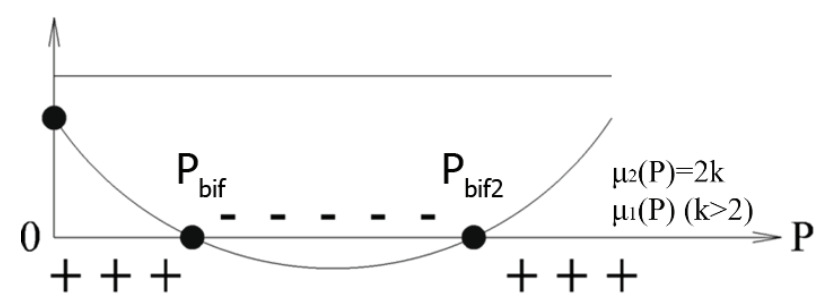

Figure 6. Curves of the trajectories of eigenvalues $\mu 1(P)$ and $\mu 2(P)$ and the stability region of the rectilinear equilibrium of the system in Fig. 10.

\section{SAMPLES OF SYSTEMS WITH RESTABILIZATION}

Let us consider a system with the restabilization of the main equilibrium under loads $\mathrm{P}>\mathrm{Pbif2}$ (Fig. 5). It consists of two compressible rods connected by an elastic-flexible hinge with a spring of rigidity $\mathrm{c}=1$. The initial lengths of the compressible rods are $\mathrm{L}=1$, the relative longitudinal rigidity is $\mathrm{K}$, the initial unbuckled equilibrium is rectilinear and horizontal. The stability of one such compressible rod with an "elastic" hinge was studied in detail by V.I. Theodosiev [8]. He constructed characteristic graphs of post-critical equilibrium curves for the state of the observing rod and investigated it stability at various combinations of stiffness and geometric parameters. T. Poston and I. Stewart [2] investigated this system heuristically to demonstrate some properties of the butterfly failure. The system was considered in more detail by M. Golubitsky and D. Schaeffer [9]. However, in their work, the curves of the post- critical ("broken") equilibriums near the point of the secondary bifurcation were constructed inaccurately.

Our interest in this system is determined by the desire to show the non-monotonic behavior of the eigenvalue $\mu 1(\mathrm{P})$ of the Hesse matrix, which allows us to obtain a re-stabilization of the rectilinear equilibrium under loads of large loads of the second bifurcation ( $\mathrm{P}>\mathrm{P}_{\text {bif } 2}$, as it is shown Figure 6).

Let $\alpha$ is the angle of deflection of the rods from the horizontal, $\mathrm{X}$ is the value of the current length of the compressible rod, $\mathrm{P}$ is the compressive load,

$$
X=(P / k) \cos \alpha .
$$

Potential energy of the system:

$$
V(k, P, \alpha, X)=k(X-1)^{2}+\frac{1}{2} \alpha^{2}+2 P X \cos \alpha
$$


Equilibrium equations:

$$
\begin{gathered}
\frac{\partial V}{\partial \alpha}=\alpha-2 P X \sin \alpha=0 \\
\frac{\partial V}{\partial X}=2(\alpha-1) k-2 P \cos \alpha=0
\end{gathered}
$$

Hesse matrix (or the Jacobi matrix of the system of equilibrium equations):

$$
\begin{aligned}
& H_{V}=\left[\begin{array}{cc}
\frac{\partial^{2} X}{\partial \alpha^{2}} & \frac{\partial^{2} V}{\partial \alpha \partial X} \\
2 & \partial^{2} V \\
\frac{\partial X \partial \alpha}{\partial X} & \frac{\partial^{2} V}{\partial X^{2}}
\end{array}\right]= \\
& =\left[\begin{array}{cc}
1-2 P X \cos x & -2 P \sin \alpha \\
-2 P \sin \alpha & 2 k
\end{array}\right]
\end{aligned}
$$

For the initial rectilinear equilibrium $(\alpha=0)$, this matrix takes the diagonal form:

$$
H(x=0)=\left[\begin{array}{cc}
1-2 P X & 0 \\
0 & 2 k
\end{array}\right]
$$

Consequently, the eigenvalues of this matrix (or stability coefficients) are

$$
\begin{gathered}
\mu_{1}(P)=1-2 P X=1-2 P\left(1-\frac{P}{k}\right)= \\
=1-2 P+2 \frac{P^{2}}{k} ; \\
\mu_{2}(P)=2 k=\text { const }
\end{gathered}
$$

From these expressions it follows that only one eigenvalue $\mu 1(\mathrm{P})$ depends on the load; the second eigenvalue $\mu 2(\mathrm{P})=2 \mathrm{k}$ does not depend on the load and is a constant number. The conditions for the equality to zero of the first eigenvalue $\mu 1(\mathrm{P})=0$ determine the bifurcation points of the basic (initial) rectilinear equilibrium of the system:

$$
\mu_{1}(P)=0 \rightarrow P_{\text {бuф1,2 }}=\frac{1}{2}\left(k \pm \sqrt{k^{2}-2 k}\right)
$$

The basic equilibrium is sustainable at loads lower than the first critical one, as well as at loads greater than the second critical one:

$$
\begin{aligned}
& P<P_{\text {биф } 1}=\frac{1}{2}\left(k-\sqrt{k^{2}-2 k}\right), \\
& P>P_{\text {биф } 2}=\frac{1}{2}\left(k+\sqrt{k^{2}-2 k}\right)
\end{aligned}
$$

(state of re-stabilization).

A square parabola describing the dependence of $\mu 1$ (P) can have either two real roots (ie, two bifurcation points) or none.

The last case occurs when $\mathrm{k}<2$. When $\mathrm{k}=2$, the two points of the bifurcation merge into one $\left(\mathrm{P}_{\text {bif }(2)}=1\right)$. Graphs of the functions $\mu 1(\mathrm{P})$ and $\mu 2(\mathrm{P})$ are shown in fig. 6.

Curves of "broken" equilibriums (initial sections) for some characteristic values of the compressibility parameter $\mathrm{K}$ are given in Fig. 7 .

The study of the bifurcation points of the basic equilibrium shows that

$$
k>2 \frac{2}{3}
$$

at symmetric points of the bifurcation, two curves of "broken" equilibriums, that grow by load, branch out (Fig. 7a). However, only one branch is stable, branching out at $\mathrm{P}=\mathrm{P}_{\text {Bifl }}$. The equilibriums that are branched out at the second point of the bifurcation $\mathrm{P}_{\mathrm{bif} 2}$, although growing, but are unsustainable. If

$$
k=2 \frac{2}{3},
$$

then on the curve of the primary "broken" equilibriums at the point of the first bifurcation, the curvature becomes zero, and further at

$$
k<2 \frac{2}{3}
$$

it becames negative. This means that at 

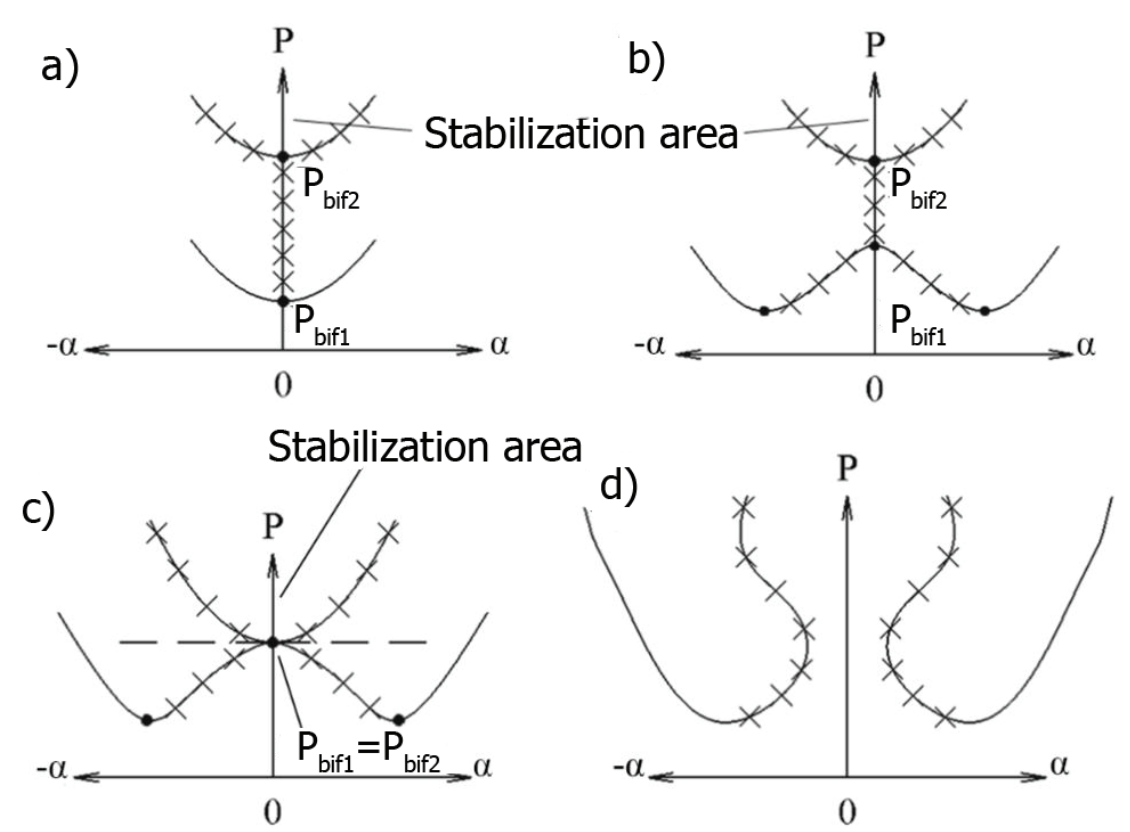

Figure 7. Sustainable state curves and areas of it stability for a two-rod system with various combinations of its stiffness and geometrical parameters:

$$
\text { a) } k>2 \frac{2}{3} \text {; b) } 2<k<2 \frac{2}{3} \text {; c) } k=2 \text {; г) } k<2 \text {. }
$$

$$
k<2 \frac{2}{3}
$$

the number of equilibriums of the system at $\mathrm{P} *$ $<\mathrm{P}<\mathrm{P}_{\text {bif }}$ there is five equilibrium points (initial and four "new" equilibriums) instead one (initial). In this case, the first point of the bifurcation from a sustainable one transforms to an unsustainable one. Consequently, at the initial part the post-bifurcation "broken" equilibriums are also unsustainable (up to the achievement of the lower ultimate point $\mathrm{P} *$ (Fig. 7b)).

At $\mathrm{k}$ value decreasing, the two points of the bifurcation approach to each other and at $\mathrm{k}=2$ it converges into one point $\mathrm{P}_{\text {bif }}{ }_{1}=\mathrm{P}_{\text {bif }} 2=1$ (Fig. 7c). When $\mathrm{k}<2$, the original rectilinear equilibrium is sustainable for all compressive loads. Any bifurcation load values disappear ("compressibility" win the aspire to loss of stability). "Broken" equilibria exist by themselves, and do not intersect with straight-line equilibria (Fig. 7c). At the same time, the branches of these equilibria that are closest to the original $(\alpha=0)$ are the branches of unsustainable saddle equilibria and form a "watershed" between the sustainable basic rectilinear equilibrium and the far equilibrium (but sustainable!) in the extreme parts of the isolated branches.

Another example of a system having zones of postcritical restoration is the "high" Mises truss (Fig. 8) with an initial angle of inclination of the rods $\alpha_{0}>67^{\circ}, 36$ (Fig. 8, b). For the Mises truss in the paper of V.I. Slivker and A.V. Perlmuther [10] the Hesse matrix is calculated. This matrix has the following eigenvalues:

$$
\begin{gathered}
\mu_{\text {бuф }}(P)=2\left(1-\frac{\operatorname{tg} \alpha}{\left(1+\operatorname{tg}^{2} \alpha\right)^{\frac{3}{2}} \cos \alpha_{0}}\right), \\
\mu^{*}(P)=2\left(\begin{array}{c}
1-\frac{1}{\left(1+\operatorname{tg}^{2} \alpha\right)^{\frac{3}{2}} \cos \alpha_{0}} \\
\alpha=\alpha(\mathrm{P}) .
\end{array}\right.
\end{gathered}
$$




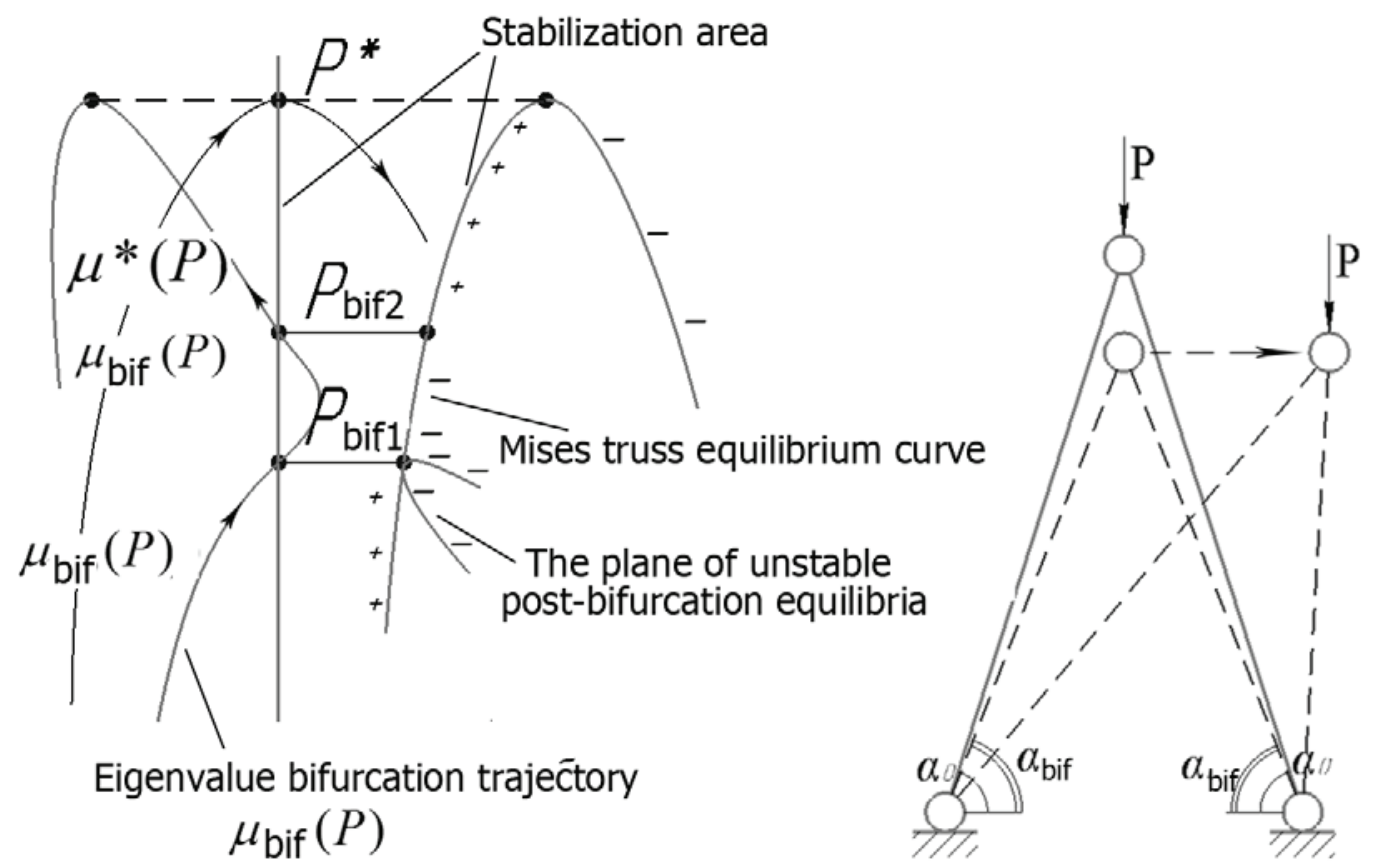

Figure 8. Equilibrium re-stabilization of the high Mises truss.

Here, the first number $\mu_{\text {bif }}(\mathrm{P})$ determines the stiffness of the truss node against horizontal perturbations, the second number $\mu^{*}(\mathrm{P})$ determines stiffness against vertical ones. The case, when stiffness $\mu_{\text {bif }}(\mathrm{P})$ becomes zero, corresponds to the moment of the bifurcation of symmetric equilibrium. The second number $\mu^{*}(\mathrm{P})$ equals to zero at the limit point. The bifurcation loss of stability of the Mises truss is possible only if the truss is sufficiently high $\left(\alpha_{0}>67^{\circ}, 36\right)$. At this value of $\alpha_{0}$, a double bifurcation point appears on the equilibrium curve, which then at large $\alpha_{0}$ angles splits into two simple bifurcation points. These points are on the ascending branch of equilibria (i.e. before reaching the limit point) if the initial tilt angle $\alpha_{0}$ is in the range of $67^{\circ}, 36$ $<\alpha_{0}<69^{\circ}, 22$.

Until the load angle $\alpha>\alpha_{\mathrm{bifl}}$, the both numbers $\mu(\mathrm{P})>0, \mu^{*}(\mathrm{P})>0$ and the symmetrical equilibrium of the truss is sustainable. When $\alpha=$ $\alpha_{\text {bifl }}$, the load is $\mathrm{P}=\mathrm{P}_{\text {bifl }}$ and the eigenvalue $\mu_{\text {bif }}$ (P) passes through zero from positive to negative values. Symmetrical form equilibrium becomes unsustainable. However, when $\alpha=\alpha_{\text {bif2 }}$ and, accordingly, the second critical load $\mathrm{P}=$

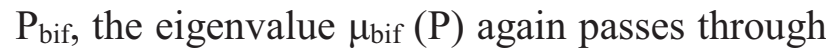
zero (from negative values to positive values). Since, in this case, the second eigenvalue $\mu^{*}(\mathrm{P})$ does not change its sign and remains positive, (until to reaching the ultimate point), then at loads $\mathrm{P}>\mathrm{P}_{\mathrm{bif} 2}$, the both eigenvalues $\mu_{\mathrm{bif}}(\mathrm{P})$ and $\mu *(\mathrm{P})$ are positive, the Hesse matrix is positively defined, and the Mises truss is again sustainable (at loads of $\mathrm{P}_{\text {bif } 2}<\mathrm{P}<\mathrm{P}^{*}$ ) (as it is shown in Fig. 8). So, for a truss with an initial angle $\alpha_{0}=68^{\circ}, 5$ critical values of the tilt angles of the rods are $\alpha_{b i f 1}=61^{\circ}, 903, \alpha_{b i f 2}=$ $47^{\circ} .347$. These values are determined by solving the equation $\cos ^{3} \alpha-\cos \alpha+\cos \alpha_{0}=0$. The corresponding bifurcation loads are calculated by the formula

$$
\mathrm{P}_{\mathrm{bif}}=2 \mathrm{cl}\left(\sin \alpha_{\mathrm{bif}}-\cos \alpha_{0} \cdot \operatorname{tg} \alpha_{\mathrm{bif}}\right), \mathrm{c}=E A / l .
$$

For the critical load at the ultimate point is $\mathrm{P} *=$ $2 \mathrm{cl} \cdot \sin ^{3} \alpha^{*}$, where the tilt angle $\alpha^{*}$ is determined from the relation $\cos ^{3} \alpha^{*}=\cos \alpha_{0}$. At $\alpha_{0}=$ $68^{\circ}, 5$ this angle is $\alpha^{*}=44^{\circ}, 305$.

The eigenvalue of the Hesse matrix is $\mu_{\text {bif }}$ at $\alpha=$ $47^{\circ}>\alpha_{\text {bifl }}\left(\mu_{\text {bif }}\left(47^{\circ}\right)=0.1437\right.$; at $\alpha=55^{\circ}\left(\alpha_{\text {bif }}=\right.$ $\left.47^{\circ}, 347<\alpha=55^{\circ}<\alpha_{\text {bif } 1}=61^{\circ}, 9\right)$ eigenvalue is negative $\left(\mu_{\text {bif }}\left(55^{\circ}\right)=-1.886\right)$; at $\alpha=47^{\circ}\left(\alpha^{*}=\right.$ $\left.44^{\circ}, 305<47^{\circ}<\alpha_{\text {bif } 2}=47^{\circ} .347\right)$ it is again positive. The re-stabilization interval is determined by the tilt angles $44^{\circ}, 305<\alpha<47^{\circ} .347$, since in this range $\mu_{\text {bif }}(\mathrm{P})>0$ and $\mu^{*}(\mathrm{P})>0$. The ap- 
pearance of the re-stabilization zone and the non-monotonous nature of the dependence of the eigenvalue $\mu_{\mathrm{bif}}$ under the load $\mathrm{P}$ is unexpected [10, p. 377]. In our opinion, the nonmonotonicity of the function $\mu_{\mathrm{bif}}(\mathrm{P})$ is explained by the fact that there are three points of critical equilibriums for trusses with initial angles $\alpha_{0}\left(67^{\circ} .36<0<69^{\circ} .22\right)$ on the ascending branch of symmetric equilibriums: two points of bifurcation and one ultimate point. Meanwhile, the Hesse matrix takes a second order, and, therefore, there are only two continuous by load $\mathrm{P}$ functions of eigenvalues $\mu_{\text {bif }}(\mathrm{P})$ and $\mu^{*}(\mathrm{P})$. The function $\mu^{*}(\mathrm{P})$ within the ascending branch is positive and zero padding at the ultimate point (at $\mathrm{P}=\mathrm{P} *$ ). For existing of two bifurcation points at loads $0<\mathrm{P}<\mathrm{P}^{*}$, the continuous function $\mu_{\text {bif }}(\mathrm{P})$ must two times "go over" through zero values: the first time from plus to minus, and the second time from minus to plus. Therefore, it cannot be monotonous, as discussed in paragraph 3. And it explains the existence of a re-stabilization zone for such forms.

\section{REFERENCES}

1. Koiter W.T. Elastic Stability and PostBuckling Behavior. // Proc. Symp. Nonlinear Problems. Madison University Press, 1963, 257 pages.

2. Poston T., Stuart I. Teoriya Katastrof i Yeye Prilozheniya [Catastrophe Theory and its Applications]. Moscow, Mir, 1980, 366 pages (in Russian).

3. Vozlinskiy V.I. Ob Ustoychivosti Tochek Vetvleniya Ravnovesiy [On the Stability of the Branch Points of Equilibria] // PMM, 1978, Vol. 42, pp. 259-267 (in Russian).

4. Vozlinskiy V.I. O Chislennoy Otsenke Oblasti Ustoychivosti. Voprosy Ustoychivosti Tochek Vetvleniya Ravnovesiy [On the Numerical Estimate of the Stability Domain. Questions of Stability of Branch Points of Equilibria]. // Teoriya ustoychivosti i yeye prilozheniya. Novosi- birsk, Nauka, 1978, pp. 94-100 (in Russian).

5. Appel P. Figury Ravnovesiya Vrashchayushcheysya Odnorodnoy Zhidkosti [Equilibrium Figures of a Rotating Homogeneous Fluid]. Moscow, Leningrad, ONTI, 375 pages (in Russian).

6. Reyyes E. Poterya Ustoychivosti Kolonny Elementarnyy Primer Bifurkatsii [Loss of Column Stability - An Elementary Example of Bifurcation]. // Teoriya Vetvleniya $\mathrm{i}$ Nelineynyye Zadachi na Sobstvennyye Znacheniya. Moscow, Mir, 1974, pp. 9-18 (in Russian).

7. Manuylov G.A., Kositsyn S.B., Begichev M.M. O Kriticheskikh i Posle-kriticheskikh Ravnovesiyakh v Zadachakh Ustoychivosti Uprugikh Sistem. // Stroitel'naya Mekhanika Inzhenernykh Konstruktsiy i Sooruzheniy, 2015, No. 5, pp. 47-54 (in Russian).

8. Feodosyev V.I. Izbrannyye Zadachi i Voprosy po Soprotivleniyu Materialov [Selected Problems and Questions of the Strength of Materials]. Moscow, Nauka, 1967, 376 pages (in Russian).

9. Golubitsky M., Schaeffer D. A Theory for Imperfect Bifurcation via Singularity Theory // Communications on Pure and Applied Mathematics, Vol. XXXII, pp. 21-97.

10. Perelmuter A.V., Slivker V.I. Ustoychivost' Ravnovesiya Konstruktsii i Rodstvennyye Problemy. Vol. 1. Moscow, SCAD Soft, 2007, 655 pages.

\section{СПИСОК ЛИТЕРАТУРЫ}

1. Koiter W.T. Elastic Stability and PostBuckling Behavior. // Proc. Symp. Nonlinear Problems. Madison University Press, 1963, 257 pages.

2. Постон Т., Стюарт И. Теория катастроф и ее приложения. - М.: Мир, 1980.-366 с.

3. Возлинский В.И. Об устойчивости точек ветвления равновесий. // ПММ, 1978, том 42 , с. $259-267$. 
4. Возлинский В.И. О численной оценке области устойчивости. Вопросы устойчивости точек ветвления равновесий. // Теория устойчивости и ее приложения. Новосибирск: Наука, 1978, с. 94-100.

5. Аппель П. Фигуры равновесия вращающейся однородной жидкости. - М.:-Л.: ОНТИ, 1936. - 375 с.

6. Рейес Е. Потеря устойчивости колонны - элементарный пример бифуркации // Теория ветвления и нелинейные задачи на собственные значения. - М.: Мир, 1974, c. 9-18.

7. Мануйлов Г.А., Косицын С.Б., Бегичев М.М. О критических и послекритических равновесиях в задачах устойчивости упругих систем. // Строительная механика инженерных конструкций $и$ сооружений, 2015, №5, с. 47-54.

8. Феодосьев В.И. Избранные задачи и вопросы по сопротивлению материалов. М.: Наука, 1967. - 376 с.

9. Golubitsky M., Schaeffer D. A Theory for Imperfect Bifurcation via Singularity Theory // Communications on Pure and Applied Mathematics, Vol. XXXII, pp. 21-97.

10. Перельмутер А.В., Сливкер В.И. Устойчивость равновесия конструкции и родственные проблемы. Том 1. - М.: SCAD Soft, 655 c.

Мануйлов Гайк Александрович, кандидат технических наук, доцент, доцент кафедры «Строительная механика» Российского университета транспорта (МИИТ); 127994, г. Москва, ул. Образцова, 9, стр. 9; тел./факс +7(499) 972-49-81.

Косицын Сергей Борисович, советник РААСН, доктор технических наук, профессор, заведующий кафедрой «Теоретическая механика» Российского университета транспорта (МИИТ); 127994, г. Москва, ул. Образцова, 9, стр. 9; тел./факс +7(499) 978-16-73;

E-mail: kositsyn-s@yandex.ru,kositsyn-s@mail.ru.

Бегичев Максим Михайлович, кандидат технических наук, доцент кафедры «Теоретическая механика» Российского университета транспорта (МИИТ); 127994, г. Москва, ул. Образцова, 9, стр. 9; тел./факс +7(499) 978-16-73; E-mail: noxonius@mail.ru.
Gaik A. Manuylov, Ph.D., Associate Professor, Department of Structural Mechanics, Russian University of Transport (MIIT); 127994, Russia, Moscow, 9b9 Obrazcova Street; phone/fax +7(499)972-49-81.

Sergey B. Kosytsyn, Dr.Sc., Professor, Head of Department of Theoretical Mechanics, Russian University of Transport (MIIT); 127994, Russia, Moscow, 9b9 Obrazcova Street; phone/fax: +7(499) 978-16- 73;

E-mail: kositsyn-s@yandex.ru,kositsyn-s@mail.ru.

Maxim M. Begichev, Ph.D., Associate Professor, Department of Theoretical Mechanics, Russian University of Transport (MIIT); 127994, Russia, Moscow, 9b9 Obrazcova Street; phone/fax: +7(499) 978- 16-73;

E-mail: noxonius@mail.ru. 